\title{
ò El pensamiento teosófico- espiritualista de Alberto Masferrer y la reacción de la Iglesia católica
}

\author{
Otto Mejía Burgos \\ Universidad Don Bosco (El Salvador)
}

Resumen: Este artículo hace un breve recorrido por el pensamiento teosófico de Alberto Masferrer, mostrando al creador del Mínimum Vital como en un principio no tenía muy claro cómo formular su idea de Dios y del mundo. Expone también como dicha tendencia -aún para los mismos discípulos del maestrose volvió confusa debido a su carácter ecléctico. Además, presenta de manera general la confrontación doctrinal e institucional que se dio entre teosofía y catolicismo durante la primera mitad del siglo XX: la teosofía bajo la tesis de que sus principios y los del catolicismo eran perfectamente compatibles, mientras que la Iglesia católica condenaba a la que veía como una serie de supersticiones y sugestiones descabelladas. Por otro lado, prueba que la obra de Masferrer es unitaria, es decir, que no se puede separar la dimensión vitalista o social de la dimensión teosófica o religiosa en su pensamiento.

Abstract: This article make a walk for the theosophical thought of Alberto Masferrer showing as the creator of the Minimum Vital theory at the beginning doesn't know how to build his idea of God and world. As well explain how that doctrine even for his supporters become confuse because it eclectic character. Also present the doctrinal and institutional confrontation between theosophy and Catholicism during the first half of the XX century: the theosophy under the creed that its principles were perfectly harmonics with the Catholicism and the Catholic Church condemning to the theosophy under the assumption was a series of superstitions and absurd suggestions. Since other perspective prove Masferrer ś work is unitary, or in other words, his theosophical dimension is intimately bound to his vitalism or social dimension. 
Palabras claves: Masferrer, Hernández Martínez, teosofía, vitalismo, décadas 20 y 30, Iglesia católica.

Keywords: Masferrer, Hernández Martínez, theosophy, vitalism, 20 \& 30 decay, catholic church.

\section{Introducción}

Muchos académicos del presente, sobre todo con inclinación de izquierda, tienden a suprimir de su análisis el pensamiento teosófico de Alberto Masferrer para quedarse sólo con el aspecto social de su obra, como sí Masferrer hubiese sido un autor de corte propiamente marxista. Aquí habría que utilizar la dialéctica hegeliana para observar la contradicción de dicha postura, ya que la teosofía precisamente aspiraba a ser un espiritualismo que se presentaría como la antítesis del materialismo "histórico" y "científico", el cual estaba muy en boga en la época que le tocó vivir al máximo propulsor del vitalismo. El intelectual actual ve en el aspecto teosófico un desvarío y una pseudo filosofía, por tanto, es algo que desecha o descarta a priori. ${ }^{1}$

Ahora bien, el panorama es muy distinto si se hace una revisión de los distintos documentos oficiales de la Iglesia católica durante las décadas de los veinte y treinta, ya que - para la Iglesia- la teosofía constituía una enemiga ideológica en expansión, es decir, la Iglesia en estos años montó todo un ataque sistemático hacía dicha doctrina, a la cual se adherían muchos intelectuales de renombre como Masferrer, Juan Felipe Toruño, Salvador Salvatierra y Salarrué. Evidentemente, la Iglesia al atacar de manera frontal a la teosofía, la convertía en una contrincante digna de tomarse en serio, es por eso que el objetivo de este ensayo primordialmente es mostrar cómo se dio tal discusión.

Desde la distancia del tiempo pareciera ser que la Iglesia veía en la teosofía a una rival que relajaba, tergiversaba y relativizaba los dogmas de la fe católica. Por otro lado, la Iglesia también atacaba a la masonería, la cual -en algunas ocasiones- estuvo ligada a la teosofía bajo la modalidad de la co-masonería. La teosofía, independientemente de los epítetos con los que se le quiera descalificar, al igual que una religión regular tiene un componente filosófico, uno religioso, uno ético y uno social. Precisamente, ahí es de donde se debe partir en la actualidad para hacer un análisis que no solamente se vuelve legítimo sino también necesario para entender el pasado. 
Siguiendo esta línea de ideas, en la primera parte de este artículo se analizarán algunas de las obras espiritualistas ya conocidas de Masferrer y su alcance, ya que en muchas ocasiones se vuelven discordantes o simplemente se malinterpretan. Luego, en la segunda parte, se mostrarán algunas de las diatribas que la Iglesia católica lanzó en contra de la teosofía, las cuales, generalmente, iban con un tono de censura, polémica y beligerancia. Cabe decir que éstas fueron publicadas en revistas o periódicos oficiales de la Iglesia o se transmitieron de viva voz en las homilías citando las respectivas cartas pastorales de condena. Al final, se elabora un balance general de ambas doctrinas haciendo un cotejo de conceptos y aportando algunas reflexiones propias.

\section{El pensamiento teosófico-espiritualista de Alberto Masferrer}

Alberto Masferrer consideraba que la teosofía, a pesar de lo abstracto de sus juicios, era vitalista, en el sentido de que abogaba por una vida íntegra e independiente de los explotadores externos. Es decir, que ésta estaba preocupada por crear industrias nacionales fuertes en países débiles y lo cual, por simple lógica, la conduciría a tener una actitud antiimperialista. Masferrer consideraba que desde una perspectiva netamente pragmática las religiones orientales eran las únicas que partían de una noción racional y moral del hombre, es por eso que todas estaban interrelacionadas formando un solo sistema que se regía bajo la ley de la conservación de la vida: vegetarianismo, pacifismo, budismo, naturopatismo, entre otras. Cabe mencionar que este último trataba de ser un método de curación natural alterno a la medicina positivista. De estas concepciones es que Masferrer aceptaría haber creado su tratado: El fundamento de la moral (Masferrer, 15 de octubre de 1929, p. 1).

Otro punto esencial en el pensamiento teosófico de Masferrer consiste en analizar cuál era su concepción de Dios y del Universo. En este sentido, Matilde Elena López pensaba que Masferrer concebía al Universo como una sola substancia que se desenvolvía mediante un mismo plan, es decir, se descomponía mediante distintas manifestaciones del "ser", por lo que su panteísmo era acorde con el sistema idealista hegeliano. En cuanto a su concepción de Dios, nos dice que para Masferrer, la deidad era "lo Absoluto, la Causa Suprema, la Causa Primera aristotélica, la Idea Absoluta, lo inefable hegeliano y como los antiguos incas y mayas adoraba al sol" (López, s.f., p. 41). 
Al parecer, Masferrer siempre estuvo construyendo y deconstruyendo su idea de Dios; en una de sus cartas escribió que uno de sus mayores errores fue establecer que existía un Dios personal como una proyección ideal del hombre bueno, concluyendo que dicha concep- ción sólo era una creación de la mente humana en búsqueda de consuelo, que es precisamente a lo que Feuerbach llamó un antroporfismo. ${ }^{2}$ Por el contrario, y desde una nueva perspectiva, estableció que existía una deidad al estilo del logos estoico, ${ }^{3}$ al cual describió como:

Un orden tremendo, irrestricto, inalterable, que no hace ni
admite excepciones. Es un orden que abarca el bien y el mal,
la compasión y la crueldad, y que revela no precisamente una
Inteligencia Suprema, sino una Voluntad Suprema. [sin corazón].
(Ley de causalidad). (Masferrer, 26 de diciembre de 1927, pp. 3-4)

Además, Masferrer creía que en cada ser humano existía "un dios o Cristo latente", preso por la naturaleza exterior. Pensaba que había una divinidad que no reconocía límites entre lo interno y lo externo, es decir que se encontraba presente en todo lo existente pero, según él, esta divinidad sólo se manifestaba mediante el ser humano -cuando éste actuaba-, ya que nunca se había podido comprobar la existencia de un Dios externo al hombre, es por eso que consideraba que Buda y otros profetas crearon religiones sin Dios. Masferrer adoptó el principio teosófico de que todo tenía una misma causa, a la cual si se quería, podía llamársele “Dios" (Masferrer, 26 de diciembre de 1927, pp. 4-5).

También sostenía que la idea de Dios era algo imposible de capturar por medio de la razón humana, por lo que ésta sólo era viable en el ámbito de la fe, en consecuencia, la ética no debía radicar en algo que no era posible conocer. Además, combatió la idea de un Dios providencial que, según él, podía ser incluso hasta perjudicial, ya que el hombre se podía volver pasivo por estar esperando cosas de Dios que podían venir de él. Masferrer creía que la responsabilidad de todos los males sociales no recaía sobre Dios sino sobre los hombres y es por eso que los hombres debían de ser sus propios redentores (Masferrer, 26 de diciembre de 1927, p. 6).

En ese sentido, en la concepción masferreriana, la religiosidad era la conciencia de la unidad entre Dios y todas las demás formas de vida que, según su grado de desarrollo, eran propensas a religarse con dicho principio único (Masferrer, 9 de septiembre de 1928, pp. 4-5). Esto quería decir que la tarea del hombre era esforzarse por realizar dicha unidad tanto en la constitución de 
la familia como en la comunidad, la nación y la federación de naciones, es decir, el hombre debía de entablar relaciones armoniosas y fraternales, tanto con sus semejantes así como con otros seres inferiores a él como animales y plantas (Masferrer, 9 de septiembre de 1928, p. 7). Desde esta perspectiva, las ideas teosóficas de Masferrer ayudaron a moldear su pensamiento social:

Si la propiedad colectiva de la tierra como elemento cósmico de la vida, como sustancia esencial de la comunidad del Estado, es la condición indispensable, la base, la necesidad absoluta de un orden social justo, armónico, que dé al hombre la posibilidad de elevarse, de realizar cada uno en sí, la idea de la Verdad Suprema (la unidad). El Mínimum Vital, es la organización aplicada a la Sociedad, de las fuerzas primarias, elementales, vitales de la tierra. (Masferrer, 9 de septiembre de 1928, p. 10)

Tal y como puede observarse en este párrafo, es clara la íntima relación que existió entre su pensamiento social y el esotérico. ${ }^{4}$ Esto también puede verificarse en sus lecturas habituales que, precisamente, eran una mezcla de ambas cosas y que generalmente fundía en una sola. En una de sus cartas familiares le escribió Hortensia ${ }^{5}$ lo siguiente:

\begin{abstract}
Estoy leyendo cuatro conferencias de Henry Georges, que compré ayer. Es algo maravilloso que nos dará mucha luz sobre la cuestión de la tierra. Mañana leeremos juntos una de ellas y un capitulo de Mahatma Gandhi. Con Josecito te envié "Magia Blanca y Negra" para que se lo pases a Bertita. (Masferrer, 14 de noviembre de 1928, p. 2) ${ }^{6}$
\end{abstract}

Esto es entendible si se observa que a finales del siglo XX proliferaron en toda América Latina una serie de movimientos religiosos muy a fines al orientalismo y ligados a corrientes esotéricas y espiritualistas. Precisamente, esta sensibilidad teosófico-oriental es la que se opuso al proyecto modernizador positivista de finales del siglo XIX, el cual veía en el indígena un factor de atraso, por eso no es de extrañar que se considere a Masferrer como uno de los pioneros de la defensa de los derechos indígenas en El Salvador y Centroamérica. Otros intelectuales que se adhirieron a estas corrientes en el continente fueron: José Vasconcelos, Alfredo Palacios, Víctor Raúl Haya de la Torre, Gabriela Mistral, entre muchos otros (Déves Váldes, 1999, pp. 137-138).

Rodríguez Cruz sostiene que Sajid Herrera en su estudio: La Universidad frente a la modernidad: esencia, 
función y misión de la Universidad en El Salvador, evidencia el fracaso del proyecto liberal y de sus efectos perjudiciales. Esta resistencia se dio a través de diferentes corrientes de pensamiento que se entrecruzaron para formar una sola respuesta y entre las cuales se podría mencionar: el hinduismo, el neoplatonismo, el espiritualismo, la teosofía y el vitalismo (Rodríguez Cruz, 2008, p. 655). Rafael Guidos Véjar menciona que Alejandro Dagoberto Marroquín en su libro: Estudio sobre la crisis de los años treinta en El Salvador, también expresa cuáles fueron estas vertientes:

a) Una orientación marcadamente anarcosocialista, con gran influencia de Tolstoi, George, Kropotkin y Marx; b) una proyección misticopanteísta en la que se adivina la presencia del pensamiento de Tagore, Vivekananda, Rama Krishna y otros teósofos importantes; c) un nacionalismo muy marcado que trataba de desarrollar una conciencia nacional junto a una nación armónica y próspera; d) una profunda vocación por la reforma social que lo lleva a plantear críticas profundas al sistema social y a proponer reformas que son combatidas por los terratenientes, por un lado y, por otro, la "izquierda extrema"; los primeros lo acusan de "bolchevique peligroso", de "agitador criminal", mientras que los segundos lo combaten por "socialista de derecha", "demagogo", "socialista utópico", carente de toda base científica", "derechista disfrazado de apariencias izquierdistas", entre otros. (Guidos Véjar, 1980, p. 21)

Por otro lado, la influencia del pensamiento teosófico de Masferrer durante la presidencia de Maximiliano Hernández Martínez (1931-1944) también fue muy marcada, sobre todo en notas y artículos dispersos que aparecían en revistas y periódicos tales como el Diario Nuevo. Sus discípulos, especialmente, sintieron admiración por su concepto de la vida, el cual estaba acoplado a cierto estoicismo y también los cautivó su teología, que consistía en una especie de "naturalismo" que caía en un "panteísmo", en el cual se podía encontrar el alma de las cosas y un raro y sutil sentido de la vida, pero a su vez consideraban- que en este entrecruzamiento de visiones no todo terminaba por encajar (Diario Nuevo, 3 de septiembre de 1938, p 3).

Nuestra incipiente ideología nos capacita para decir a que escuela puede pertenecer este ilustre publicista salvadoreño; 
fue un iniciado en la teogonía brahmánico-budista y no le fueron desconocidas las doctrinas teosóficas. De las enseñanzas de Jesús y de Buda formó, en sus libros y artículos, una especie de "eclecticismo", que en algunos casos sería muy difícil, mejor dicho imposible sostener en buena filosofía. (Diario Nuevo, 3 de septiembre de 1938, p. 5)

Los seguidores de Masferrer aludían al hecho de que su pensamiento esotérico, efectivamente, tuvo múltiples contradicciones, por ejemplo, la doctrina de Jesús era profundamente individualista y propendía a la conservación del "yo" aún más allá de la muerte, mientras que en la concepción búdica, el individuo desaparecía y su alma se confundía con la especie (nirvana): "como la gota de agua en el océano". Sus admiradores, honestamente, en ese momento, admitían no entender a cabalidad su "sincretismo" y pensaban que sí Masferrer hubiese estado vivo les hubiese dicho: "nuestra filosofía comienza donde termina la vuestra". (Diario Nuevo, 3 de septiembre de 1938, p. 5)
Por su parte, Marta Casaús cree que obras como Helios, Estudios y figuraciones sobre la vida de Jesús y La religión universal han sido mal interpretadas en razón del desconocimiento de sus cartas privadas como retornos de Masferrer al catolicismo o a la heliosofía, lo cual, según ella, no era su intención, sino más bien oponerse al ultramontanismo del clero a través del libre pensamiento. (Casaús, 2012, pp. 250-251). En realidad, a nuestro criterio, la libertad de pensamiento de Masferrer era algo mucho más amplio, ya que trataba de contrarrestar a todos aquellos sectores que pretendían poseer verdades absolutas y estáticas, lo cual quedó demostrado en su artículo "El hombre culto":

El hombre culto se caracteriza por su tolerancia, curiosidad mental, serenidad, respeto y desinterés en presencia de la verdad nueva. Se caracteriza por el recelo de vivir en el error, y por su fervorosa disposición a cambiar de ideas, en presencia de una verdad superior, una verdad superior es, necesariamente, de mayor amplitud e integralidad que aquella verdad a quien supera (...) un hombre culto es, necesariamente y en la máxima expresión de la palabra, UN LIBRE PENSADOR. Un libre pensador se mantiene siempre en actitud independiente de las ideas reinantes, costumbres, credos políticos, sociales y religiosos (...) se mantiene libre, sobre todo, respecto de sí mismo, y dispuesto a tirar por la borda el contenido íntegro de su mente, si una luz más clara le hace ver que ese contenido es de calidad inferior. (Masferrer, 5 de noviembre de 1929, p. 1) 
Para la académica, todas las obras teosóficas de Masferrer, pero principalmente La religión universal tienen una aspiración regeneracionista y utópica, ya que pretenden forjar un hombre nuevo infundiendo en él, valores positivos a manera de un catecismo laico (Casaús, 2012, p. 254). Desde nuestro punto de vista, independientemente de lo que haya dicho Masferrer en sus cartas, La religión universal fue la adopción explicita e híbrida de dos de los objetivos fundamentales que promueve toda Sociedad Teosófica: 1) formar una fraternidad universal y 2) ser un estudio comparado entre diversas religiones, objetivos que Masferrer hizo suyos integrando ciertos principios éticos de diferentes religiones (Casaús, 2012, p. 268).

El centro del pensamiento ético de Masferrer era el hombre, y para moralizarlo recurrió a diferentes credos, por ejemplo: conservar la vida de todos los seres (incluso no humanos) era un principio budista. Además, esta religión consideraba que el hombre no tenía que ser opresor, ni ejercer la violencia contra nadie. De las religiones, Masferrer también recogió el postulado de que no había que acaparar la tierra, ni el agua, ni el aire, ni la luz, porque eran elementos que pertenecían a todos (Masferrer, 1968b, pp. 6-10).

Para Masferrer, la esencia de toda religión era ser compasivo con todo el que sufría. En La religión universal también hizo alusión a la ley del karma cuando dijo: "lo que siembras cosecharás". También equiparó los conceptos de Sol, Dios y Orden, cuyas potencias eran: verdad, justicia y amor, y abordó la ley de la reencarnación y otros principios teosóficos como el de fraternidad. Al igual que en Estudios y figuraciones sobre la vida de Jesús, aseveró que vendría un mesías que realizaría una familia universal (Masferrer, 1968b, pp. 12-20).

Masferrer, precisamente, en esta última obra abordó el tema bíblico de la anunciación mariana, es decir, cuando María anunció que iba a dar a luz al Salvador del mundo. Masferrer visualizaba a Jesús como un libertador, sobre todo del pueblo de Israel, que a través de la historia ha tenido diferentes dominadores: persas, griegos, romanos, entre otros. Establecía que Jesús proclamó un "Reino Universal" que tendría por cabeza a Jerusalén y que esto ya había sido anunciado por profetas como Juan el Bautista, quien creía en la venida de un mesías. En esta dirección, Masferrer narra la historia bíblica de cuando Herodes mandó a hacer una matanza de niños para evitar la llegada del rey de los judíos, el cual -como estaba escrito- los libertaría (Masferrer, 1972, pp.13-27).

En este libro también abordó ideas propiamente teosóficas como la que ya hemos mencionado sobre la deificación del hombre, lo cual 
él comprobaba mediante frases del mismo Jesús que afirmó: "Sed perfectos como vuestro Padre que está en los cielos" (Mateo 5:48). Masferrer concebía a Jesús como el Superhombre de Nietzsche, ya que entendía a este Superhombre como un hombre "ideal" o "modelo". También en este ensayo se encuentran presentes las ideas de la fraternidad universal y del Uno ontológico, cuando Masferrer expresa que Cristo intentó hacer una sola familia bajo una paternidad celestial única. Masferrer visualizaba a Jesús como un ser extrahumano, fruto del Espíritu Santo que había encarnado en la pureza más sublime, haciendo alusión a la ley del karma (Masferrer, 1972, pp. 32-36).

Para Masferrer, debido al karma puro de Jesús, éste nunca sufrió de enfermedades, ya que éstas eran formas de castigos físicos del espíritu, lo cual comprobaría su credo en la reencarnación e hizo una hibridación entre ideas teosóficas y cristianismo. Además, Masferrer estableció que Jesús fue un revolucionario de las ideas, porque rompió con todas las creencias establecidas antes a él, quizá también estaba hablando de sí mismo cuando dijo que habría de llegar un reformador o un salvador de hombres, porque el nuevo redentor al igual que Jesús no sería violento ni guerrero, sino un hombre espiritual (Masferrer, 1972, pp. 38-68). De hecho, Tránsito Huezo a este respecto dice: "(Masferrer) fue un visionario que se adelantó a su época, un ferviente imitador de Jesús que se desarrolló similar a Tagore, y un paladín de la justicia”. (Huezo, 1940, p. 11).

En esta obra, Masferrer también especuló sobre que Jesús visitó las ciudades de Tiro, Sidón y Damasco donde perfeccionó su griego y aprendió las doctrinas de Pitágoras y Platón. En éstas también conocería a hombres que le hablarían de las doctrinas de Buda, Lao-Tsé y Zoroastro, por lo que Jesús, mediante estos viajes pretendería construir una religión a fin de formar de la humanidad una sola familia sin castas, clases o diferenciaciones de razas. (Masferrer, 1972, pp. 79-107).

Habría que señalar que el pensamiento espiritualista de Masferrer estaba muy a tono con el del futuro presidente de El Salvador (Maximiliano Hernández Martínez), quien pensaba que todos los seres eran espíritu y que del espíritu se formaba la materia. En el fondo, Hernández Martínez era pitagórico, en el sentido de que creía en un gran geómetra del Universo que creaba o "construía" con base al número y las matemáticas. En principio, los números serían realidades intangibles a través de las cuales este dios animaba todas las formas: lo largo, lo ancho y lo redondo. Luego Platón asumiría estas enseñanzas como parte de su doctrina secreta. Para Platón, como principios creadores, 
más alto que las ideas estaban los números. Lo que haría la teosofía sería reagrupar toda la multiplicidad sensorial en un principio espiritual de la cual todas las cosas dependen: el Uno (Mejía Burgos, 2014, pp. 470-472).
El hecho de que todos los seres provinieran del Uno, significaba que todos eran hermanos y de ahí se deriva el principio de la Fraternidad Universal de la teosofía (Mejía Burgos, 2014, p. 470). Al respecto, Hernández Martínez manifestó en una de sus conferencias - la cual fue publicada en el Diario Nuevo- lo siguiente:

\begin{abstract}
Si invocamos a Dios con entera fe, el pan espiritual del que habla la oración universal -la tuvieron los más antiguos pueblos y la tienen los actuales- llegaría hasta nosotros con prodigalidad. Más nos dejamos dominar por el egoísmo y de este modo la historia del mundo es la historia de las guerras sucesivas. (Diario Nuevo, 8 de enero de 1941, pp. 1-2)
\end{abstract}

En realidad,Masferrer fue bastante provocador al sostener que Jesús fue el único que predicó el verdadero "comunismo", el cual consistía en dar al que no tenía. La radicalidad y autenticidad del comunismo cristiano primitivo, desde su perspectiva, consistía en estar libre de teorías y en no constituir un sistema complejo e intricado, sino más bien en ser una actitud de vida práctica antes que inútil palabrería, la cual debía de predicarse de forma sencilla sin hacer alusiones a la economía, a la ciencia o a la historia. Para él, Jesús predicó sencillamente el derecho que tenía todo hombre de comer y vestirse, reafirmando su esoterismo cuando estableció que Jesús fue un conocedor de la "gnosis", lo cual quería decir que fue un "iniciado" (Masferrer, 1972, pp. 112-113).

La gnosis, que es a un tiempo ciencia y religión, ley moral y ley física, síntesis que explica cuanto es capaz el hombre de comprender sobre el origen y la vida del Universo, se halla esparcida y fragmentada en el espiritismo, en la teosofía, en la alquimia, en la astrología, en la masonería, en las visiones de Swedemborg, en la kabala, en la religión de Moisés y de Mahoma, en la católica, en Pitágoras, en Platón, en Plotino. (Masferrer, 1972, pp. 79-107). 
Según Masferrer, estos cono- trarle sentido a la vida no hay que cimientos habían permanecido pertenecer a ninguna religión en ocultos para evitar interpretaciones concreto sino que es el mismo hombre torpes. Para entenderlas a cabalidad había que ser un iniciado, es por eso que Juan el Bautista inició a Jesús mediante el sacramento del agua, que era el primer grado de iniciación; el segundo era la comunión con el pan y el tercero, la comunión con el Espíritu Santo. Es decir, Masferrer percibía a Jesús y a Juan como dos iniciados en las doctrinas secretas y aseguraba que el primero diseminó la doctrina del verbo enseñada por Platón. (Masferrer, 1972, pp.130-141).

En su ensayo Helios, Masferrer también sostiene que para enconquien debe darse una divinidad para religarse o reestablecer un vínculo con lo divino (religión), es decir, el hombre debe buscar donde poner su fe para no caer en el nihilismo en el que cayó Nietzsche. La asunción de esta deidad, Masferrer la encontraría en el Sol, ya que Masferrer era consciente de que sin el astro rey no podría haber vida sobre la Tierra, él es el posibilitador más grande. Aparte de esto, es un dios viviente porque lo ve, lo siente y recibe sus beneficios todos los días: (Masferrer, 1968a, pp. 158-159).

Nuestro Dios es el Sol. De su luz nacimos, de su luz vivimos, y en su luz desaparecemos. Él sabe también a quien adora, y tiene su Dios, un Sol aún más divino, a quién yo no sé ni concebir. Y ese otro Dios, sabe también a quien adora; iy así hasta el Corazón del Universo!... (...) ¡Oh, Sol! ¡Oh, Padre! ¡llumínanos, guíanos, purifícanos, enciéndenos en tu lumbre divina, y venga la hora en que toda oscuridad y tristeza se desvanezcan en tu alegría y tu esplendor...! (Masferrer, 1968a, pp. 159-160).

Para Masferrer, el Sol no era nada más que la manifestación física y contingente de otro principio único, invisible y necesario. El Sol, por tanto, era un ser muy inferior a esta Causa primera, pero en él estaba manifestado una minúscula parte del poder del gran hacedor del Universo. El Sol también trataba de encontrar a su Padre, aunque los hombres no pudieran tener acceso a él y es por eso que, según Masferrer, en ciertas religiones antiguas estaba prohibido mencionar el secreto y verdadero nombre de Dios, el sólo mencionar su nombre era signo de profanación. La cuestión era que el hombre no podía aspirar a entender lo que por su propia naturaleza limitada no podía entender y he ahí el gran misterio para todas las religiones. (Masferrer, 1968a, pp. 159-161). 
Ahora bien, Masferrer en Las siete cuerdas de la lira realizó una cosmogonía en la cual estableció que antes de la materia existía la nada y que de la nada surgió todo. Este todo era la materia que en un principio se encontraba en caos y que luego se armonizó hasta formar esferas. La substancia única evolucionó y formó la luz que es a lo que el maestro llamó "éter". Según Masferrer, en el mundo existían siete ritmos o vibraciones que determinaban todas las escalas de la vida. (Masferrer, 2002, pp. 23-15).

Estos siete fluidos eran distintos modos de la materia: la tierra (lo solido), el agua (lo liquido), el aire (lo gaseoso), el fuego (lo que dilata y transforma), la energía (lo que da vida y movimiento), la atracción (lo que unifica) y la luz (lo que hace ver y comprender). De los siete fluidos combinados surgía una diversidad infinita de mundos. Estos siete fluidos eran las siete cuerdas de la lira. De estos siete elementos surgía todo lo existente y se transformaban unos en otros, por ejemplo, el agua podía convertirse en aire, el aire en fuego y el fuego en luz, es decir, la materia sólo se transformaba (Masferrer, 2002, Pp.16-18).

Los estados no estaban contrapuestos sino compenetrados unos en otros. Los hombres también eran manifestaciones híbridas de estos siete fluidos, porque para Masferrer, el ser humano era esen- cialmente energía y había sido moldeado mediante un ritmo que lo constituía. Los estados de la materia corporizaban los elementos, pero no alteraban su naturaleza esencial. Las personas también estaban constituidas por el cuerpo o sustancia material, el alma o sustancia anímica y el espíritu, que organizaba o modelaba la forma. La energía en el alma humana se manifestaba mediante la voluntad, la persistencia y la obstinación (Masferrer, 2002, pp. 19-37).

Para Masferrer, estos fluidos siempre estaban en constante transformación, los distintos estados no eran más que maneras de vibrar, sólo que siempre había predominio de un fluido que caracterizaba cada forma. Uno de los fluidos más intangibles para Masferrer era la ley de atracción. En un fluido líquido siempre estaba latente un fluido sólido y viceversa. Los fluidos no eran nada más que distintas vibraciones del éter. Para Masferrer, las formas eran concentraciones de fluidos, puso ejemplos como el agua, la tierra, el fuego y la luz que, según él, constituían distintas combinaciones de elementos. Todo "ser" era un esquema del Universo (Masferrer, 2002, pp. 27-40).

Ahora bien, hemos dicho que Las siete cuerdas de la lira es esencialmente una cosmogonía. Una cosmogonía es una especie particular de mito, un mito de los comienzos. Mircea Eliade explica que los mitos son importantes porque propor- 
cionan modelos de conducta humana y proveen de sentido a la existencia, generalmente, se entienden como meras ficciones, pero son ficciones que siempre van dirigidas a hechos o sucesos reales, por ejemplo: todas las religiones están fundamentadas en mitos y éstos constituyen la verdad para sus feligreses. Todas las sociedades conservan ciertos mitos y son a los que Eliade llama "mitos vivos" (Eliade, 1973, pp. 14-16).

Mediante una cosmogonía, el hombre establece su relación con el eterno retorno, o sea, mediante la actualización que realiza de dicho mito éste se está religando constantemente. Además, las cosmogonías de las diferentes culturas y etnias proporcionan distintos relatos de por qué los hombres y el mundo han llegado a ser como son. La cosmogonía de Masferrer no es la excepción, ya que abarca todo lo existente. Ahora bien, habría que preguntase por qué Masferrer escribió una nueva cosmogonía en plena modernidad. Eliade nos dice que el hombre moderno ya no se siente obligado a reconocer los mitos; los ve como relatos mágicos irrelevantes que deberían de haberse superado desde hace mucho tiempo, es decir, que desde su mentalidad racionalista ya no le significan nada (Eliade, 1973, pp. 18-25). Quizás, ahí radique la respuesta:

\begin{abstract}
Tal fue el pensamiento cosmológico griego antes de que Sócrates, al descubrir la razón, cambiara mediante su humanismo crítico el giro de la mentalidad helénica. Masferrer se coloca ante las cosas con intentos exhaustivos y para ello emprende la marcha hacia el principio cronológicamente inevitable (...) La exposición anterior nos recuerda de relieve a los cosmólogos cuyas doctrinas sintetizó magistralmente Empédocles al ofrecer la teoría de los 4 elementos. (Tales de Mileto: agua, Heráclito: fuego, Anaxímenes: aire, Jenófanes: tierra) Las fuerzas vital y unitaria remontan trasuntos mecanicistas antiguos. Elementismo y mecanicismo parecen ser los rasgos de la Cosmogonía masferreriana. (Guandique, 1943, p. 1)
\end{abstract}

Esto quiere decir que Masferrer construyó una cosmogonía rudimentaria similar a la de los mayas o presocráticos como una forma de criticar el proceso modernizador que amenazaba con destruir todos los mitos. En este sentido, Juan Antonio Estrada sostiene que la filosofía surgió del mito y que ésta siempre se ha movido en un contexto mitológico, cree que aunque la reflexión crítica rechaza de forma global el mito, éste ha sido su punto de partida e inspiración. Desde su perspectiva, no es que el mito sea irracional sino que posee una racionalidad simbólica 
que, precisamente, da en qué pensar. Además, cree que los mitos son una forma legítima de conocimiento y de acceso a la realidad en los cuales está inserto el propio proyecto existencial de la humanidad (Estrada, 1997, pp. 43-45) y es por eso que Masferrer, en este relato, pasa de inmediato de su cosmogonía a su antropología:

\begin{abstract}
Masferrer al tratar temas de antropología concluye lo que ha iniciado. Su antropología remata su Cosmogonía. Y, además cumple un urgente imperativo histórico ya que existe una enorme preocupación contemporánea por los problemas relativos al hombre. Casos relevantes abundan. Unamuno apoyándose en la repetida tragedia de lo vivido. Scheler desde la posición esencialista. Kierkegaard con su problema teológico. Todos quieren explicarnos al ser humano... (Guandique, 1943, p. 1)
\end{abstract}

Una vez tratado a grandes rasgos el pensamiento religioso de Masferrer, se debe entrar a la segunda etapa de interés de este artículo, lo cual es conocer cuál fue la postura de la Iglesia católica respecto a él y a sus ideas, ya que en ese tiempo, el catolicismo se consideraba como la única institución autorizada para abordar asuntos teológicos y espirituales.

\title{
2. Reacción de la Iglesia católica frente al pensamiento teosófico de Masferrer
}

Al mismo tiempo que Masferrer difundía su pensamiento teosófico, el periódico católico El Tiempo lo criticaba de forma enjundiosa. En general, lo acusaba de ser anticientífico y antifilosófico, en parte debido a que Helena Blavatsky en su obra La Doctrina Secreta, específicamente en el volumen II, atacaba la ciencia moderna y por tanto, al positivismo y al darwinismo. Esta crítica, según el redactor católico Vicente Martínez Lemus fue retomada por Masferrer en Las siete cuerdas de la lira, obra que acabamos de analizar. Además, dicho autor arremete en contra de Masferrer porque sostenía, según él, lo que era una cosmovisión animista del mundo y una metafísica que se basaba en el principio único panteísta. La Iglesia, en general, creía que todo este imaginario provenía de la teósofa y masona inglesa Annie Besant y su visión de los siete planos astrales (Martínez, 8 de enero de 1930, pp. 1-8).

Asimismo, la Iglesia a través de este periódico deslegitimó la antropología teosófica que se fundam- 
entaba en siete principios, según lo expresó el mismo Masferrer en la ya citada obra: "materia, forma, vitalidad, animalidad, mentalidad, espiritualidad y divinidad", de lo que se concluía que el hombre era un "animal divino". Atacaron fuertemente su idea del cuerpo "astral" o "sutil", que era un estado intermedio entre lo etéreo y lo material que -aseguraban- ya existía antes de Platón en el Ka egipcio, en el Manas de los Veda y en la Linga Sharira de los sankias prebúdicos. El clero concluía que era una concepción "salvaje", porque de ella se derivaba el culto a los muertos y antepasados, por tanto, también condenaban el espiritismo (Martínez, 18 de enero de 1930, pp.1-8).
Otro punto fundamental que refutaban de la teosofía, era la idea de la reencarnación bajo el supuesto de que el "ser perfecto" estaba compuesto por un cuerpo y por un alma, los cuales coexistían sin que pudiera vivir el uno sin el otro, sino solo simultáneamente, es decir, negaban rotundamente la teoría de la preexistencia de las almas y de la reminiscencia, basados en obras como las de P. Romero Benedet, S.J. La plaga del espiritismo moderno, Cap. IV. Entonces, para los católicos, Dios creaba las almas en el momento de ser "infundidas" en los cuerpos y se desintegraban en el momento de la muerte:

\begin{abstract}
Anduvo, por consiguiente, muy errado don Alberto Masferrer, cuando escribió en su Ensayo sobre el Destino: "Así pues, la muerte no cambia en nosotros nada esencial.” ¡Cómo! ¿Qué no cambia en nosotros nada esencial? Desintegra por completo la naturaleza humana, destruye al hombre, en cuanto tal; puesto que separa sus constitutivos esenciales, cuerpo y alma. (Martínez, 25 de enero de 1930, pp. 1-7)
\end{abstract}

Masferrer defendió la idea de la reencarnación en su Ensayo sobre el destino, al decir que la actual vida física era precedida por muchas otras mediante el proceso de la transmigración de las almas, es decir, el traslado del espíritu en diferentes cuerpos, en donde el espíritu creaba la nueva forma o cuerpo en el que habría de reencarnar para entrar de nuevo a la vida. A esta idea venía unida la ley del karma, mediante la cual el hombre reencarnaba dependiendo de sus acciones en la vida anterior, que era como una especie de retribución moral. Frente a estas posturas, la Iglesia católica aceptaba, obviamente, la creencia en el infierno cristiano como castigo (Martínez, $8^{\circ}$ de febrero de 1930, p. 1) y la teoría judía de la resurrección de los cuerpos: (Martínez, $1^{\circ}$ de febrero de 1930, pp.1-8). 
Pero dígame Ud., Don Alberto, ¿Quién ha dado al alma o espíritu, separado de su cuerpo propio, el poder de formarse un nuevo cuerpo? ¿Los teósofos acaso? Pero ¿quiénes son los teósofos para disponer a su talante y voluntad de un poder, que pertenece exclusivamente, a la divina Omnipotencia? Porque Dios solo es el creador y organizador de la materia; Dios solo, el que puede reintegrar la humana naturaleza, desintegrada por aquélla: como lo hará, sin duda, el día de la resurrección de la carne. (Martínez, $1^{\circ}$ de febrero de 1930, pp. 1-8).

Estos enfrentamientos entre teosofía e Iglesia católica no fueron exclusivos en El Salvador, según Esteban Rodríguez Dobles, en su ensayo Conflicto en torno a las representaciones sociales del alma y los milagros. La confrontación entre la Iglesia católica y la Sociedad Teosófica de Costa Rica (1904-1917), también desataron grandes controversias al interior de la sociedad costarricense, aunque en otros casos, teósofos y católicos llegaron a convivir en paz. ${ }^{7}$ Rodríguez Dobles expresa que la Sociedad Teosófica costarricense tuvo fuertes vínculos con la masonería y que las acusaciones que la Iglesia católica lanzó en contra de ésta, también fueron utilizadas para atacar a la teosofía, aunque aclara que en ambas instituciones había marcadas diferencias (Rodríguez Dobles, 2010, pp. 88-90).
El académico establece que estos conflictos surgieron como consecuencia de que estas nuevas representaciones o imaginarios constituían un peligro para el ejercicio del poder eclesial. Desde la psicología de Nietzsche, se diría que la teosofía constituía una afrenta a la "voluntad de poder" de la Iglesia, mediante la cual pretendía establecer un predominio de sus representaciones. Las representaciones son creencias $u$ opiniones de ciertos individuos o grupos, que tratan de hacerse prevalecer en un medio social concreto. (Rodríguez Dobles, 2010, pp. 91-92).

Las representaciones teosóficas fueron confrontadas y desacreditadas por la Iglesia en sus distintos órganos oficiales, en Costa Rica, por ejemplo, mediante los periódicos $L a$ Patria y La Época, en los cuales se publicaban ataques sistemáticos a los teósofos, a quienes generalmente se les acusaba de cometer fraudes en distintos sentidos, tales como: 1 ) moverse por intereses puramente especulativos con el afán de obtener dinero, 2) constituir una seudoreligión, 3) fabricar una sincretismo ilógico y 4) plagiar ciertos credos de la religión cristiana. Incluso, en 1913 dicha confrontación llegó a extremos insospechados cuando un sacerdote católico le prendió fuego al recientemente construido Templo Teosófico en aquel país (Rodríguez Dobles, 2010, pp. 101-104). 
La teosofía en Costa Rica surgió en un ambiente de profundas transformaciones sociales, políticas y económicas. Chester Urbina en su ensayo Iglesia, Estado y control mental en Costa Rica: el caso de la prohibición de la enseñanza de la teosofía en el Colegio Superior de Señoritas (1922), sostiene que sus primeros adeptos fueron un pequeño grupo de extranjeros e intelectuales que no aceptaban el monopolio que de la fe hace la Iglesia, a la cual veían como ultraconservadora y retrograda (Urbina Gaitán, 2015, p. 54).

Evidentemente, la Iglesia no quería perder su statu quo o hegemonía cultural, la cual había sostenido durante largos siglos. Otro ejemplo de ello fue que monseñor Rafael Otón Castro escribió una carta pastoral donde manifestaba que no era lícito inscribirse en las sociedades teosóficas costarricenses o leer sus publicaciones. En Costa Rica, también hubo otro caso particular, se acusó a la directora del Colegio Superior de Señoritas Esther de Merzerville y a un profesor del mismo colegio, el Ingeniero Enrique Jiménez Núñez, de estar divulgando la teosofía en el interior de dicha institución educativa. Se afirma que después de la polémica sólo una estudiante se retiró y en cambio, entraron cinco más (Urbina Gaitán, 2015, pp. 54-55).

La entrada de ciertas ideas teosóficas en instituciones católicas también se ha interpretado como un proceso de secularización que la Iglesia venía experimentando desde el siglo XIX, esto según el análisis de Iván Molina, quien identificó dicho movimiento como una reacomodación de credos en 1904, o sea, se crearon nuevas modalidades de religiosidad a partir de las reformas introducidas por el Estado liberal. (Urbina Gaitán, 2015, pp. 56-57).

El hecho en concreto era que lo permitiesen 0 no las autoridades gubernamentales, las ideas teosóficas circulaban con fuerza en distintos centros educativos que estaban en proceso de laicización, por lo que la teosofía quedaba como en una especie de limbo entre lo viejo que ya no se creía y lo nuevo que aún no se aceptaba. La ventaja de la teosofía en este proceso era que tomaba los credos cristianos tradicionales sin excluirlos de otras formas de religiosidad, lo cual, evidentemente, conllevaba una crítica a la ortodoxia católica intolerante, pero al mismo tiempo tampoco suprimía todo tipo de conocimiento de fe revelada, ideal propio del proyecto modernizador positivista. Ahora bien, esta visión jamás podría ser aceptada ni por la Iglesia ni por la ciencia oficial.

También debe recordarse que muchas de las reformas secularizadoras fueron iniciadas por miembros activos de la masonería y es por eso que hubo una lucha contra el liberalismo en general. El liberalismo 
se fundamentaba en el racionalismo ilustrado que evidentemente se oponía a todo tipo de dogma o mito (Martínez Esquivel, 2009, pp. 13-15). Ahora bien, pareciera ser que tanto la teosofía como la masonería no llevarían este principio al extremo, ya que en ambas estaba presente la creencia en una deidad, o sea, que ambas actuarían como formas religiosas laicizadas no ateas o agnósticas, de ahí que también hubiera personas que pertenecieran a ambas instituciones. Es por eso que la Iglesia igual que atacó a la teosofía atacó a la masonería, incluso, Ricardo Martínez piensa que desarrolló una "guerra de ideas" promulgando 16 documentos oficiales antimasónicos escritos entre 1738 y 1894, los cuales posteriormente llegarían a Costa Rica y a toda Centroamérica. (Martínez Esquivel, 2009, p. 16).

\section{Conclusión}

En conclusión, la teosofía llegó a tener un gran impacto social no sólo en El Salvador sino en toda la región centroamericana durante las décadas de los 20 y 30, hecho que hizo reaccionar de forma enérgica a la Iglesia católica en relación a esclarecer cuál era la sana doctrina de Cristo frente a lo que concebía como "sectas" o sociedades "desorientadoras". Así lo demuestra la Décima Carta Pastoral de monseñor Luis Chávez y González, la cual en su versión manuscrita llevaba por título La teosofía cotejada con el cristianismo, ésta fue dictada en una visita canónica hecha a la Parroquia de Santo Tomás, ubicada en Santiago Texacuangos, el día 25 de diciembre de 1932 (Chávez y González, 1932, p. 23).

En la misma, el clérigo establecía que toda persona más o menos instruida había tenido conocimiento de las doctrinas teosóficas, las cuales habían calado muy hondo en la mentalidad del pueblo no sólo a través de la difusión de material especializado propio de iniciados, sino también a través de periódicos de circulación nacional comunes y corrientes. Esta afirmación es bastamente comprobable durante la presidencia de Hernández Martínez si se toma en cuenta la gran variedad de artículos de esta naturaleza que aparecían tanto en los periódicos oficiales como privados, es decir, la teosofía era algo mucho más popular y aceptado de lo que en la actualidad se imagina.

El malestar de monseñor Chávez y González iba encaminado a que la teosofía aspiraba a tener el mismo estatus de la Iglesia, incluso hasta el punto de suplantarla mediante la creación de sociedades como la llamada "Iglesia católica liberal", la cual tenía como único propósito confundir a la feligresía. En este sentido, el objetivo de la carta era 
demostrar que la teosofía y el catolicismo eran completamente incompatibles e irreconciliables. Chávez y González, en definitiva, sostenía que la teosofía constituía una apostasía al credo cristiano (Chávez y González, 1932, p. 1).

Por otra parte, el jerarca exhortó a los fieles a no dejarse engañar con falacias y enredos extravagantes e impropios de la cultura salvadoreña. A los teósofos consumados les hizo un llamado a rectificar en su error y a reconciliarse con la Iglesia. Desde esta perspectiva, los teósofos serían como una especie de hermanos extraviados a los cuales había que reencauzar por el buen camino. Según la Iglesia, los tres grandes problemas que se planteaba la teosofía eran: ¿Qué es Dios? ¿Qué es el mundo? y ¿Qué es el hombre? Este último también abarcaba el aspecto moral. (Chávez y González, 1932, p. 4). El meollo del asunto era, pues, que estas preguntas existenciales sólo podían ser respondidas de manera adecuada por la Iglesia, por lo que con base a la referida carta, a continuación se presenta un cuadro comparativo donde se resaltan las discrepancias entre ambas visiones:

\begin{tabular}{|c|c|}
\hline Dios para el catolicismo: & Dios para la teosofía: \\
\hline $\begin{array}{l}\text { Concepción de un Dios vivo, verdadero, } \\
\text { omnipotente e infinitamente perfecto } \\
\text { en inteligencia y voluntad. (Chávez y } \\
\text { González, 1932, p. 4). }\end{array}$ & $\begin{array}{l}\text { Concepción panteísta que negaría la exis- } \\
\text { tencia de un Dios real y vivo, bajo el principio } \\
\text { de que Dios es todo y todo es Dios. (Chávez y } \\
\text { González, 1932, p. 4). }\end{array}$ \\
\hline El mundo para el catolicismo: & El mundo para la teosofía: \\
\hline $\begin{array}{l}\text { El mundo, por esencia es completamente } \\
\text { diferente a Dios. Dios es una substancia } \\
\text { espiritual singular, por tanto, no se puede } \\
\text { confundir con el mundo. } \\
\text { Dios, en un acto libre y amoroso, creó } \\
\text { de la nada el mundo material. Dios con } \\
\text { su inteligencia y voluntad gobierna el } \\
\text { mundo. (Chávez y González, 1932, p. 5) }\end{array}$ & $\begin{array}{l}\text { Es la variedad de seres; es Uno en multipli- } \\
\text { cidad. Dios no se diferencia esencialmente del } \\
\text { mundo. (Chávez y González, 1932, p. 4) }\end{array}$ \\
\hline Antropología católica: & Antropología teosófica: \\
\hline $\begin{array}{l}\text { Cada hombre constituye una persona } \\
\text { dueña de sus actos y se compone física- } \\
\text { mente de un organismo material llamado } \\
\text { cuerpo y de un principio vital llamado } \\
\text { "alma". }\end{array}$ & $\begin{array}{l}\text { El hombre emana del cosmos por evolución } \\
\text { progresiva después de sufrir largas transforma- } \\
\text { ciones y en fuerza de evolución regresiva ha de } \\
\text { retornar a su origen, resolviéndose con el todo. } \\
\text { (Chávez y González, 1932, p. 6). }\end{array}$ \\
\hline $\begin{array}{l}\text { El alma constituye la actividad superior } \\
\text { intelectual y volitiva del hombre. (Chávez } \\
\text { y González, 1932, p. 5). } \\
\text { El hombre se gana con buenas obras } \\
\text { la gloria del cielo, es decir, el hombre } \\
\text { al morir va al cielo en proporción a sus } \\
\text { méritos y sin perder su personalidad } \\
\text { (Chávez y González, 1932, p. 6). }\end{array}$ & $\begin{array}{l}\text { El hombre al morir es regido por la ley del } \\
\text { karma, es decir, continúa su existencia a través de } \\
\text { otras vidas, lo cual implica que el hombre renace } \\
\text { en repetidas ocasiones con el objeto de vivir } \\
\text { períodos de purificación. (Chávez y González, } \\
\text { 1932, p. 6). Esta es la teoría de metempsicosis } \\
\text { o transmigración de las almas de Platón, la cual } \\
\text { permanece viva en las religiones orientales. } \\
\text { (Chávez y González, 1932, p. 7). }\end{array}$ \\
\hline
\end{tabular}


Dimana de la Biblia mediante revelación, es decir, la moral cristiana se funda en la voluntad de Dios de la cual se inspiran la ley natural y la ley positiva. (Chávez y González, 1932, p. 12)

Utiliza como método la oración, que sería como una especie de conversación con Dios.

La meditación cristiana es persuasión. (Chávez y González, 1932, p. 11).
Dimana de muchas fuentes, principalmente del budismo y del hinduismo, es decir, la teosofía contiene un sincretismo ético.

Propone una moral altruista y humanitaria con base en una especie de religiosidad laica.

Uno de los métodos para practicar esta moral es el yoga que son ejercicios de penitencia usados por los budistas con el objeto de moderar las pasiones.

Otro punto de la moral teosófica son los hábitos ascéticos tales como el vegetarianismo (Chávez y González, 1932, p. 10) y la meditación budista. (Chávez y González, 1932, p. 11).
Para la Iglesia, creer en las enseñanzas teosóficas constituía un pecado grave (Chávez y González, 1932, p. 7). La única opción para los teósofos, en definitiva, era aceptar la redención de Jesucristo según los evangelios (Chávez y González, 1932, p. 8). Esto suponía que la verdad sólo podía venir por revelación, en ese sentido, cualquier afirmación o creencia que no coincidiera con las Sagradas Escrituras constituía una desviación a la sana doctrina cristiana (Chávez y González, 1932, p. 9). Evidentemente, Masferrer era un hombre de opinión pública, dirigía un periódico y era muy reconocido en el ámbito intelectual de su época, todas estas circunstancias -a los ojos de la Iglesia- lo hacían muy influyente entre la feligresía católica que lo admiraba o que simplemente simpatizaba con sus ideas. De este modo, el catolicismo emprendió un feroz ataque contra un Masferrer que ni siquiera era un teósofo insti- tucional, es decir, hasta donde se sabe - salvo prueba de lo contrariono perteneció a ninguna sociedad teosófica, tal como fue el caso de Martínez, Salarrué o Salvatierra, pero la cuestión era que el sólo hecho de realizar un panegírico de la teosofía lo volvía blanco de los distintos ataques de la alta jerarquía católica.

Otro punto muy importante de resaltar es que - no obstante- todos los argumentos que presentó la referida Iglesia en aquella época (años 20 y 30), el general Maximiliano Hernández Martínez tuvo muy buenas relaciones con ella, incluso después de los eventos de enero de 1932 se comportaron como estrechos aliados. A todas luces, dicha alianza se explica por el hecho de que la Iglesia veía un peor enemigo en el comunismo que en la teosofía o la masonería, con las cuales no se ponía en riesgo el sistema de vida occidental. Por otro lado, hasta el día de hoy hay 
miembros activos de la teosofía que también son católicos, en ese sentido, caerían en una situación muy similar a la de los católicos-masones con todas las contradicciones que esto implica. Tales fusiones demostrarían que los imaginarios sociales en ocasiones son mucho más complejos $\mathrm{y}$ amoldables de lo que las doctrinas rígidas pudieran suponer o esperar. Nuevas líneas de investigación tendrían que profundizar en la cuestión: ¿la teosofía y la masonería se volvieron modos liberales alternos de ver la verdad? Específicamente, ¿la teosofía salvadoreña surgió como una reacción al materialismo ateo del marxismo? y ¿si surgió como una alternativa espiritual de corte laico al absolutismo e intolerancia de la misma Iglesia?

\section{Referencias bibliográficas}

- Casaús, M. E. (2012). El libro de la vida de Alberto Masferrer y otros escritos vitalistas (Edición crítica de la obra teosófico-vitalista (19271932). Guatemala: F\&G Editores.

- Casaús, M. E. (2010). El Vitalismo de Alberto Masferrer y su impacto en el pensamiento de América Central. Revista Cultura (Nº.102), p. 78.

- Chávez y González, J. A. (1932). Décima Carta Pastoral: La teosofía cotejada con el cristianismo. Recopilación del Archivo del Arzobispado de San Salvador, pp. 3-23.

- Déves Váldes, E. (1999). Redes teosóficas y pensadores (políticos) latinoamericanos 1910-1930. Cuadernos Americanos, (78), pp. 137-152.

- Plática del Presidente anoche en el pro-patria. (8 de enero de 1941). Diario Nuevo, pp.1-2.

- Eliade, M. (1973), Mito y realidad. Madrid: Ediciones Guadarrama.

- Estrada, J. A. (1997) La imposible teodicea, (la crisis de la fe en Dios). Madrid: Editorial Trotta.

- Guandique,J.S.(20 de noviembre de 1943).Alberto Masferrer:pensador, Francisco Gavidia: humanista, Juan Cotto: poeta. Diario Latino, p. 1. 
- Guerra, V. M. (2014). Alberto Masferrer y su quehacer intelectual: una búsqueda sincera de la justicia social. p. 5

- Guidos Véjar, R. (1980). El ascenso del militarismo en El Salvador. San Salvador: UCA Editores.

- Homenaje a Alberto Masferrer, el más grande filósofo, maestro y estilista salvadoreño. (3 de septiembre de 1938). Diario Nuevo, p. 3.

- Huezo Córdova, T. (3 de septiembre de 1940). Alberto Masferrer. La Prensa Gráfica, p. 11.

- López, M. E. (s.f.) Pensamiento Social de Alberto Masferrer. San Salvador: Imprenta Nacional.

- Martínez Esquivel, R. (2009). Conspiradores políticos y sectas misteriosas: imaginarios sociales sobre la masonería en Costa Rica (18651899). Revista Estudios, pp. 13-32.

- Martínez Lemus, V. (8 de febrero de 1930). El karma teosófico y el infierno cristiano. El Tiempo, pp. 1.

- $\quad$ (1 de febrero de 1930). Las reencarnaciones teosóficas. El Tiempo, pp. 1 y 8 .

$\bullet$ El Tiempo, pp. 1 y 7. . (25 de enero de 1930). La pluralidad teosófica de vidas. . (18 de enero de 1930). El cuerpo sutil de los teósofos y el astral de los espiritistas. El Tiempo, pp. 1 y 8.

1 y 8. . (8 de enero de 1930). El mundo teosófico. El Tiempo, pp.

- Masferrer, A. (2002). Las siete cuerdas de la lira. San Salvador: Dirección de Publicaciones e Impresos CONCULTURA.

. (1972). Estudios y figuraciones sobre la vida de Jesús. San Salvador: Dirección de Cultura del Ministerio de Educación. 

de espíritu y cuerpo. Archivo General de la Nación, pp. 3 y 4.

- (9 de septiembre de 1928). Escribiendo el libro la "Verdad Suprema". Archivo General de la Nación, pp. 4 y 5.

- (1968b). La religión universal. San Salvador: Ministerio de Educación.

. (5 de noviembre de 1929). El hombre culto. Patria, p. 1.

. (15 de octubre de 1929). El Estado debe satisfacer las necesidades primarias de los hombres. Patria, p. 1.

. (14 de noviembre de 1928). Carta a Hortencia. Archivo General de la Nación. p. 2.

. (26 de diciembre de 1927). Carta comunicando una depresión

. (26 de noviembre de 1927). Lectura del libro karma-yoga. Archivo General de la Nación, p. 1.

- Mejía Burgos, O. (2014). El proyecto de nación masferreriano y su recepción durante la presidencia de Maximiliano Hernández Martínez. Tesis de doctorado en Filosofía Iberoamericana. UCA, p. 174.

- Molina,J. (2001). Teología y racionalidad en la filosofía estoica. Anuario del Centro de Estudios Clásicos, Nova Tellus, (N. 19, 2). pp. 109-153.

- Nóchez, M. L. (2013). Masferrer, los filósofos también lloran. El Faro. Recuperado de: https://elfaro.net/es/201306/el_agora/12260/ Masferrer-Los-fil\%C3\%B3sofos-tambi\%C3\%A9n-lloran.htm

- Rodríguez Cruz, Agueda y otros. (2008) Pensadores y forjadores de la universidad latinoamericana. Venezuela, Universidad Central.

- Rodríguez Dobles, E. (2010). Conflicto en torno a las representaciones sociales del alma y los milagros. La confrontación entre la Iglesia 


\author{
católica y la Sociedad Teosófica de Costa Rica (1904-1917). Revista \\ REHMLAC, pp. 88 y 90.
}

\author{
- Urbina Gaitán, Ch. (2015). Iglesia, Estado y control mental en Costa \\ Rica: el caso de la prohibición de la enseñanza de la teosofía en el \\ Colegio Superior de Señoritas (1922). Revista Ciencias Sociales, (150), \\ pp. 53-61.
}

\title{
Notas
}

1 Víctor Manuel Guerra Reyes, tanto en su tesis doctoral como en su libro Alberto Masferrer y su quehacer intelectual: una búsqueda sincera de la justicia social, deja de lado el estudio de la teosofía. En esta última obra establece: "La finalidad de este trabajo es mostrar la obra intelectual de Masferrer, cosa que implica un esfuerzo de desmitificación de su pensamiento desde una propuesta de reconstrucción de su figura y obra intelectual, ya que lo que se ha dado a conocer de él es, sobre todo, el aspecto poético, el escritor idealista y el teósofo para los intelectuales". (Guerra, 2014, p. 5). Otro caso puede ser el de Matilde Elena López, quien en su obra sobre Masferrer aparte de ciertas menciones esporádicas de la teosofía, no profundiza en ella, ya que su énfasis lo hace en la dimensión política y social del pensador.

2 La idea de un Dios personal aparece en Estudios y figuraciones sobre la vida de Jesús (1972, p. 52).

3 El Dios o (logos estoico) es el principio hegemónico del universo y se encuentra presente en todo él. La teología estoica demuestra la existencia de un Dios basada en que en el universo hay un orden racional y teleológico del mundo. Podría clasificarse como un monismo materialista: Dios y el mundo se confunden como un todo continuo, orgánico y racional. (Molina, 2001, pp. 109-153).

4 Masferrer también fue apoyado por teósofos y unionistas centroamericanos como: Salvador Mendieta, Alberto
Velásquez y Joaquín Rodas: "Este círculo estaba dominado por algunas sociedades teosóficas guatemaltecas, hondureñas y nicaragüenses a las que pertenecían intelectuales como Flavio Guillén, Carlos Wild Ospina, Tácito Molina Izquierdo y José Miranda y especialmente el grupo de teósofos unionistas quezaltecos..." (Casaús, 2010, p. 78).

5 Aparentemente, Masferrer tuvo una intensa vida sentimental con Hortencia Madriz, lo cual marcó los últimos años de su vida. Esta relación ha podido ser descubierta a partir del intercambio epistolario privado y clandestino entre ambos. Esta sería la última mujer a quien Masferrer amaría y con quien procrearía una hija que actualmente vive en Bélgica. También influyó mucho en su obra: "En 1926, tres años antes de publicar "Helios" y "La religión universal", Masferrer confesaba a Hortensia que "conocerla le ha devuelto la esperanza de un dios que tanta decepción le ha provocado durante su vida". (Nóchez, 2013).

6 Masferrer estaba profundamente influenciado por el libro Karma-yoga de Swami Vivekananda, el cual -según sus mismas palabras- leyó en varias ocasiones por estar lleno de una gran sabiduría. (Masferrer, 26 de noviembre de 1927, Lectura del libro karma-yoga, p. 1).

7 "Esto puede comprobarse cuando Jinarajadasa establece que, aunque sabe que la Iglesia católica moderna condena la teosofía, a través del tiempo, también han habido algunos esfuerzos por conci- 
liar ambas doctrinas mediante obras como: Transacciones de la Sociedad de Filadelfia publicada por feligreses católicos en 1697, Introducción a la teosofía vista como los misterios de Cristo, obra dirigida específicamente a estudiantes de universidades, colegios y escuelas cristianas y Misceláneas teosóficas y guía de lo espiritual, publicada en 1675 por el sacerdote católico Miguel de Molinos. Todas con el ánimo de aprovechar las ideas teosóficas por la religión cristiana". (Mejía Burgos, 2014, p. 174). 